\title{
Apparatuses of observation and occupation: Settler colonialism and space science in Hawai'i
}

EPD: Society and Space $0(0)|-2|$

(C) The Author(s) 2021

(c) (1) \&

Article reuse guidelines: sagepub.com/journals-permissions DOI: | 0.1 | 777/026377582। I042374

journals.sagepub.com/home/epd

\section{Katherine G Sammler (D)}

California State University Maritime, USA

\section{Casey R Lynch}

University of Nevada, USA

\begin{abstract}
This paper examines two space science infrastructures in Hawai'i, the Thirty Meter Telescope (TMT) and the Hawai'i Space Exploration Analog and Simulation (HI-SEAS). It considers how scientific observation and colonial occupation are co-constituted through the production of apparatuses - extensive material practices and arrangements that iteratively produce subjectobject relations. By analyzing TMT and HI-SEAS as apparatuses, we show how both involve the active ordering of space, time, and matter in ways that are dependent upon existing settler colonial relations while enacting specific subject positions key to the projection of settler colonialism across space and time. TMT materializes the Archimedean point, or view-from-nowhere, on which Western scientific "objectivity" depends, while HI-SEAS works to produce ideal colonizer-subjectivities and orient their bodies to the spatialities of the colony. Engaging Native Hawai'ian, Indigenous, and allied anti-colonial critiques, we argue that social science of outer space research must critically address the colony, as its basic logics are foundational to the practices of contemporary space science and imaginaries of space exploration.
\end{abstract}

\section{Keywords}

Hawai'i, settler colonialism, space-time, apparatus, social science of outer space

\section{Corresponding author:}

Katherine G Sammler, Helmholtz-Institute for Functional Marine Biodiversity (HIFMB), Ammerländer Heerstrasse 23I, 26I29 Oldenburg, Germany.

Email: ksammler@hifmb.de 


\section{Introduction}

The hope in the observation of the Venus transit was that it might help unlock the key to the universe's mapping and offer astronomers the ability to calculate distances between celestial bodies in earth's home galaxy... Not content with the boundaries imposed by gravity, oceans, or ice, Europeans sought possession of all their eyes could see. (Byrd, 2011: 2)

In The Transit of Empire, Jodi A. Byrd describes Enlightenment logics that motivated British Captain James Cook's late-18th century voyages to the South Pacific. The goal of Cook's first voyage, commissioned by the Royal Society, was to observe the 1769 transit of Venus - a rare astronomical event in which Venus passes between Earth and Sun, visible as a small black dot moving across the star's bright surface. The event's periodicity results in two transits separated by an eight-year period then not again for over one hundred years. Viewing the transit offered observers a unique opportunity to gain insight into the size of our solar system and map distances between celestial bodies. In the history of European colonialism, the scientific objectives of Cook's voyages are often overlooked in relation to his role in initiating colonization of Australia and New Zealand and, later, Hawai'i and much of the South Pacific. Yet, as Byrd describes, the transit of Venus is inextricably tied to broader projects of European colonization, not only by Cook's voyage, but also by common logics linking observation, possession, and domination.

After the transit event, Cook and the HMS Endeavour crew claimed many Pacific Islands for the British Empire. During this purported 'Age of Discovery,' observation and occupation corresponded through international law. As Shaw describes, "[o]ccupation, both in the normal sense of the word and in its legal meaning, was often preceded by discovery, that is the realisation of the existence of a particular piece of land" (2003: 425). In other words, the mere realization or sighting was "sufficient to constitute title to territory" (Shaw, 2003: 425). Two-hundred and fifty years after Cook's astronomical observations from his makeshift observatory in Tahiti, Pacific Islands continue to serve as important sites for the production of astronomical knowledge by colonial institutions.

Hawai'i is home to key sites in an extra-global network of space science infrastructure through which national, university, and private space agencies produce knowledge about the universe and plan the expansion of "humanity" beyond Earth's atmosphere. The Hawaiian archipelago's tallest mountain is home to 13 observation facilities within the Mauna Kea Science Reserve and is regarded as a premier site on Earth for astronomical observation. Since 2014, Kanaka Maoli (Native Hawaiian) land protectors have been locked in a heated political and legal battle to prevent construction of the Thirty Meter Telescope (TMT), sparking arguments around the politics of science and the ongoing colonization of Hawai'i (Brown, 2016; Casumbal-Salazar, 2017; Goodyear-Ka'ōpua, 2017; Maile, 2015). On nearby Maunaloa, the Hawai'i Space Exploration Analog and Simulation (HI-SEAS) has been used by NASA researchers to simulate a Mars habitat, where would-be Mars colonizers experiment with human adaptation to life on the red planet.

While other imaginaries are possible (Sammler and Lynch, 2019), this paper demonstrates how Western space science projects are inextricably entangled in the imaginaries and practices of settler colonialism (Prescod-Weinstein, 2020; Smiles, 2020). We refer to offworld colonies not to reproduce this imaginary but to recognize that this is the project being carried out by both traditional public space agencies like NASA and emerging private space industries. The paper examines HI-SEAS and TMT to consider the complex imbrications between historical, ongoing, and projected future settler colonialism and ideologies 
and practices of Western space science. HI-SEAS and TMT seemingly represent very different projects. While TMT defenders describe the telescope as a passive and innocuous piece of infrastructure used to produce "universal" knowledge, HI-SEAS presents a more active form of exploration towards offworld colonization. Yet, examining the two projects in relation, we show how both rely on logics of colonial totality (Matson and Nunn, 2017), the existing material relations of the colony, and the erasure of lived Native peoples and places (Hobart, 2019), while enacting distinct yet co-dependent subject positions key to the projection of settler colonialism across space and time. TMT and HI-SEAS, respectively, enact the disembodied god's-eye-view of Enlightenment science and the idealized Enlightenment subject-body of the colonizer.

While we are not the first to recognize the co-constitution of observation and occupation, by highlighting this relationship in TMT and HI-SEAS, we set up a critical dialog between Indigenous and anti-colonial critiques and interdisciplinary literature on social studies of outer space (SSOS). SSOS literature explores how socio-technical projects of visualization produce astronomical knowledge (Vertesi, 2015); how space agencies simulate Moon and Mars with earthly analogs (Olson, 2018) superimposing spaces onto one another (Messeri, 2016); and how offplanet activities reshape geopolitics, environmental politics, and resource economies (Dunnett et al., 2019; Klinger, 2021). Others examine space science infrastructures as projects of state-building, displacement, and development in colonial contexts (Mitchell, 2018;Redfield, 2002). While many of these authors recognize that offworld activities are within colonial imaginaries and practices, anti-colonial critiques are not often made explicit, focusing instead on the perspectives and actions of scientists and engineers (Messeri, 2016).

In contrast, Indigenous and allied critical scholars offer analyses of spatial and temporal logics of settler colonialism as manifested through space science infrastructures and their related imaginaries (Maile, 2015; Matson and Nunn, 2017; Smiles, 2020). For TMT, scholars examine the multiple practices, logics, and institutions of Western space science that have worked to lay claim to Native Hawai'ian lands. Hobart (2019: 42), for instance, examines how TMT has been justified through narratives that reframe Maunakea within imaginaries of scientific progress in which the site "transcend[s] international politics in the name of the greater good of humanity" as part of a longer historical trajectory of discursively emptying or "deanimating" landscapes. Goodyear-Ka'ōpua argues that settler temporality reserves modernity and futurity for colonial projects and relegates Indigeneity to a premodern past, but that TMT activists "enact Indigenous futurities and open space to transform present settler colonial conditions" (2017: 185). Casumbal-Salazar makes clear that TMT controversies cannot be understood without explicitly questioning settler colonialism, writing:

How are we to understand the controversy over Mauna a Wākea and the TMT if we fail to identify or accept the context in which this battle is being waged; if we fail to critically analyze settler-colonization under U.S. occupation? (2017: 24)

Unseating the purported universality and objectivity of space science projects requires categorical anti-colonial analyses.

We argue that Barad's (2007) theorization of the apparatus is useful for bridging SSOS and anti-colonial scholarship because it traces techno-scientific production as part of broader apparatuses extending spatially and temporally from what is traditionally understood as the sites and moments of scientific practice. Through the apparatus, we show how projects of scientific observation and colonial occupation are co-constituted through the 
production and maintenance of space science infrastructures on colonized lands. In turn, we consider how these infrastructures reproduce the subject-object relations key to settler colonial projects - the view-from-nowhere (or Archimedean point) and embodied colonizer subjectivities. Observation is never a passive enterprise; rather, observation-occupation is active and employs apparatuses to iteratively enact differences between subject and object, colonizer and colonized.

This paper is based on digital archival work. We collected and analyzed video, textual, and photographic material related to the two sites. For TMT, this focused on economic and physical development of Maunakea as a site for space observation, construction of a summit access road, and Hawaii's centering as an optimal astronomy locale. Sources included historical accounts, promotional documents, astronomy publications, land management policy, land protector social media communiqués, and Native Hawaiian scholarship and reporting on the construction and blockade. For HI-SEAS, we examined digital archives from the six NASA-sponsored missions, blog posts by mission participants, media coverage, published interviews with HI-SEAS officials, and scientific articles based on HI-SEAS research. This analysis allows us to trace the material production of these two sites and the broader imaginaries they work to uphold. We author this paper recognizing our positionality as white settlers who benefit from the ongoing occupation of Native and Indigenous lands and privileging of colonial knowledge in academia. We are motivated to deconstruct these projects by our experiences and positions within the white supremacist settler colonial patriarchy to define observation apparatuses as part of violent occupation logics and practices.

\section{Settler colonial space-times}

[T] he idea of a closed system [is] a concept that was constituted by the island laboratory and the irradiated atoll and perpetuated by the aerial view. (DeLoughrey, 2012: 168)

The links between space science, Western imperialism, and settler colonialism are not confined to the history of Cook's voyages or the settler colonial conditions of contemporary Hawai'i. Rather, they are entangled in ongoing histories of the Enlightenment in which ideologies of European superiority - used to justify violent conquest and pillaging of Indigenous lands - rely upon claims of scientific objectivity, modernity, universality, and futurity (Byrd, 2011). In this section, we situate TMT and HI-SEAS in the history of colonial imaginaries of islands as abstract laboratories for scientific experimentation. We then consider how this erasure of space is entangled with Western conceptions of time that relegate Indigeneity to the past while producing linear, progressive futures (Goodyear-Ka'ōpua, 2017). We bring these reflections together through Barad's notion of the apparatus, which we employ to critically examine TMT and HI-SEAS.

\section{Island laboratories}

Since Cook's expeditions, the West has subjected the constellation of Pacific Islands to a multitude of science experiments (DeLoughrey, 2012; Farbotko, 2010). Salmond (2003: ix) explains how "[a]s the edges of the known world were pushed out, wild nature - including the 'savages' and 'barbarians' at the margins of humanity - was brought under the calm, controlling gaze of Enlightenment science, long before colonial domination was attempted." 
There is a long history of the liveliness of islands being abstracted by colonial powers and scientists alike, from seemingly innocuous use of the Galápagos as discrete microcosms for theorizing evolution (Matsuda, 2006); to the United States' devastating testing of nuclear weapons on the Marshall Islands; to botany's role in the colonization of Hawai'i and its extension into contemporary experiments with genetically-modified organisms replacing native plant species (Goldberg-Hiller and Silva, 2015). As with other landscapes, specific imaginaries of place play a unique role in colonial practices on islands. Continental views of islands align with Enlightenment scientific desire for blank slates, perfect laboratories (Greenhough, 2006; Matsuda, 2007). Mobilizing imaginaries of frontier and isolation, representations of islands within a continental and colonial gaze are, as Matsuda explains, "distant, isolated, uninhabited, and abstract spaces" (2007: 230). The purported distance of the island colony enacts a separation between colonizer and colonized landscape that allows for specific relations and forms of observation. Islands become simplified models of a complex world, acting as "quintessential sites for experimentation" (Baldacchino, 2007: 165) based on fetishized assumptions about island spatiality.

Scientists use islands to isolate variables and substitute space for time to construct linear timestreams. Islandness functions as stand-in for a computational time-step within an experimental design. These purported blank slates endow the initial time-step essential to modelling. Islands and their peoples have been employed to examine theories of geological, biological, human, and socio-cultural evolution. DeLoughrey describes how island spatiality is considered bound by "the theme of isolation, a model that had been deployed in the 19th century to propose the theory of evolution, and which re-energized the longstanding colonial understanding of the island as a laboratory" (2012: 168). The expansion of U.S. empire specifically enrolled island colonies from Puerto Rico to the Philippines as sites for grisly experimentations, from weapons to biomedical research on non-white bodies who were seen as relics of earlier stages of evolution (Immerwahr, 2019).

Just as islands and their peoples have been used to model past evolutions, they are also established as models for specific futures. Baldacchino describes islands

as sites of novelty; they tend toward clairvoyance; they are disposed to act as advance indicators or extreme reproductions of what is present or future elsewhere... with fallacious simplicity, [they] can be conceived as a convenient platform for any whim or fancy. (2007: 165)

Islands have emplaced visions of future climate dystopias (Farbotko, 2010) and imagined libertarian capitalist utopias (Lynch, 2017). The continuation of these projects of empire and white supremacy are shaping plans for human colonization of Moon and Mars. Such projects re-articulate debates around questions of race, ability, eugenics, reproduction, and human psychology in journals like Futures - including a 2019 special issue on ethics in offworld colonization.

Through these projects, islands and peoples are erased and overwritten by the totality of the model world they represent. As DeLoughrey explains, "Western colonizers had long configured tropical islands into the contained spaces of a laboratory, which is to say a suppression of island history and Indigenous presence" (2012: 172). An affective landscape of history, more-than-human relationality (Watts, 2013), and lived social place gets transformed into independent, sterile variables instrumentalized in the projection of specific futures. Such discourses intersect with space science imaginaries of exploration, exoticism, and otherworldliness. 


\section{Settling time}

As an empire of time rather than space... many significant American national theorists sought to escape the political paradoxes of space by conquering time. (Allen, 2008: 13)

Allen examines how U.S. empire depends upon three notions of time: a romanticized historical time recounting myths of the nation's founding, the geological time of natural history, and the mechanized time of the clock and apparatuses of measurement. The organization and control over these three temporalities constitutes a colonial totality (Matson and Nunn, 2017) that works to settle time as much as space in the projection of settler futures.

The projection of settler futures depends on the ordering of time, constituted by ideologies of progress, of a mythologized past and present oriented toward the future. Scientific "progress" is positioned as a universal value key to constructing the future, while questioning the actions of Western science is positioned as irrational or reactionary. Concerning the TMT controversy, Casumbal-Salazar writes:

Relegated to the 'dark ages' of tradition, Native peoples appear as the agonistic menace of the modern scientific state. Delegitimized as irrational within the gendered hierarchies of Western science and philosophy... Hawaiians become suspect and subject to institutional anti-Native racism yet fetishized as an archeological remnant within multicultural society. (2017: 2)

In dominant discourses, Indigenous time is linked to the past, with the present constituted on assimilation and the future on complete erasure (Rifkin, 2017). The existence of contemporary Indigenous peoples poses a challenge to ongoing settler colonial hegemony. Goodyear-Ka'ōpua explains how "settler state officials cast the kia"i [land protectors, caretakers] as impediments on the road to 'progress' (aka settler futurity) ... (mis)representing us as fixed in place, pinned in a remote time" (2017: 191-192). Enlightenment notions of universality erase difference and thus Indigenous claims to prior rights or sovereignty. While these conceptions of time have long been critiqued, they continue to shape the central logics of contemporary Western science, including space science.

Linear conceptions of time are necessarily produced out of complex practices that organize and control relative and variable spatio-temporal formations. Rifkin posits a multiplicity of temporalities, writing:

temporalities need to be understood as having material existence and efficacy in ways that are not reducible to a single, ostensibly neutral vision of time as universal succession. The concept of frames of reference provides a way of breaking up this presumed timeline by challenging the possibility of definitively determining simultaneity... Within Einsteinian relativity, simultaneity depends on one's perspective based on one's frame of reference. (2017: 20)

Einstein's theory of relativity demonstrates how time is relative, variable, and dependent on acceleration, which is a function of location within a gravitational field. It is a relationship between space, masses, and matter. As Valentine explains:

gravity is a consequence of the relational warping of spacetime by matter... That is, gravitational effects are literally universal but emerge locally through relativistic and constantly shifting specific relations among the mass of cosmic bodies and spacetime, producing variable observations from differently situated observers of one another (2017: 189-190). 
The practices of Western astronomy are dependent on variable and relative relations among space and time. Whether it is earth-bound astronomers punching the clock on Martian time (Mirmalek, 2020) or the stretching of temporal experience in a gravity well, the location of bodies matters as it produces 'differently situated observers,' who experience time differently based on their frames of reference. Yet, time is held as a stable frame of reference from which the colonial scientist constitutes the metric for a purportedly universal observer situated in a neutral position of observation. Even Western science's own understanding of time refuses to conform to Enlightenment notions of universality, demonstrating a contradiction between this ontology and the broader political and social ideologies with which it is entangled.

While notions of linear, progressive time are used to justify settler colonial projects, the relative and contingent relationships among space, time, and matter complicate claims to universality. Time, like space, is subject to practices of organization and control that produce subject-object relations key to the Western colonial project. For instance, geologic time, or what Allen refers to as "vertical time," is the spatial-temporal imaginary of geologic strata. He describes that, while "history often depicted time advancing horizontally across space, the geological revolution made it possible to imagine time extending perpendicularly into the territory beneath the nation" (Allen, 2008: 165). The deep time of geology historicizes Western civilization as the top layer, the apex of natural history, and thus stands to justify colonialism and its civilizational projects. The exploration of cosmological time in the space sciences extends the colonial project further into the far expanses of the future and the totality of the universe.

\section{The apparatus}

Gazing out into the night sky or deep down into the structure of matter, with telescope or microscope in hand, Man [sic] reconfirms his ability to negotiate immense differences in scale in the blink of an eye. Designed specifically for our visual apparatus, telescopes and microscopes are the stuff of mirrors, reflecting what is out there... Man is an individual apart from all the rest. And it is this very distinction that bestows on him the inheritance of distance, a place from which to reflect-on the world, his fellow man, and himself. A distinct individual, the unit of all measure, finitude made flesh, his separateness is the key. (Barad, 2007: 134, emphasis added)

In Barad's deconstructive reading of Enlightenment science, linear time and evacuated space are both the product of active material processes through which a purportedly universal "Man" continually enacts a separation between himself and the universe. It is this supposed separation from the rest of existence that constitutes "Man" as the subject of a masculinist science and the remainder of the universe as the object of his will. Practices of scientific observation and colonial occupation work in tandem to re-enact and reinforce this fundamental subject-object relationship. Critical scholars of science have long argued against the purported passivity of observation, from critiques of the Archimedean point (Yaqoob, 2014) to feminist theories of the embodied and situated nature of knowledge production (Haraway, 1988). Yet, beyond simply noting the ontological impossibility of Man's separation from the universe, Barad theorizes an emergent and contingent form of separability - what she calls agential separability - that is (re)produced through the material practices of apparatuses. Barad explains that "apparatuses enact agential cuts that produce determinate boundaries and properties of entities within phenomena" (2007: 148). Apparatuses determine what comes to matter and how, thus producing differences between 
subject and object, which are not stable positions but rather enacted and contingent forms of relationality.

We employ the apparatus to explore how subject-object relations of Western colonial science are not universal and absolute, but rather enacted through material practices that selectively produce the privileged subject positions on which settler colonialism and space science both depend. Barad's theory of spacetimemattering highlights the mutual constitution of space and time through the ongoing material re-configuring of the world. Apparatuses are

neither neutral probes of the natural world nor social structures that deterministically impose some particular outcome... the notion of an apparatus is not premised on inherent divisions between the social and the scientific... [they] are the practices through which these divisions are constituted. (Barad, 2007: 169)

Reconceiving subjectivity, objectivity, space, time, and matter in this way implies that questions of ethics are inseparable from apparatuses as practices that produce differences and iteratively construct the world. Apparatuses enact material changes through which some possibilities are realized while others are foreclosed.

Ontologically, apparatuses produce spatial, temporal, and material relations that constitute projects of Western colonial science. This approach helps elaborate arguments like those of Matson and Nunn that "even the most futuristic space telescopes have embedded within them a lineage of Euro-western cultural supremacy" (2017: n.p.). This is not to simply claim that telescopes are in some way symbolic of settler colonial relations, but to recognize how space science apparatuses actively orient relations of observation and materialize settler colonial relations.

Both TMT and HI-SEAS constitute apparatuses that extend spatially well beyond the infrastructural footprint on these mountains, to the island and surrounding ocean, into the atmosphere, to Moon, Mars, and cosmos. As part of these apparatuses, mountain environments of Hawaii become both a gateway to the cosmos and simulation of an alien landscape. Temporally, the apparatus stretches beyond contemporary scientific practices, drawing on longstanding histories of European imperialism, Western law, and settler colonial logics, and projecting these ideologies into offworld futures. Materially, these projects enroll technological, logistical, and physical systems, including roads, mirrors and lenses, sensors and surveillance devices, electromagnetic waves and domes, the geology of the Hawaiian landscape, and bodies of observer and observed.

\section{Mirrors and domes}

[S]pace as the 'final frontier' is not simply a metaphor but speaks to the role of astronomy in upholding the ongoing projection of values onto new territories and extending power and acquisition of territory to those complicit in colonial processes. This extends both to the world's highest peaks and into the heavens. (Matson and Nunn, 2017: n.p.)

We examine the spacetimemattering of TMT and HI-SEAS through the analytic of the apparatus (Barad, 2007), showing how agential cuts are made through each of these projects to reproduce subject-object relations and manifest settler colonial logics in spacetime. We trace how the TMT apparatus materializes the Archimedean point, an idealized view-fromnowhere, that is key to historical and contemporary forms of both scientific knowledge and 
colonial power. In the case of HI-SEAS, we follow the apparatus' work to perfect ideal colonizer-subjects and orient their bodies to the colony. Put in conversation, these cases demonstrate the material production of two distinct but entangled subject positions and sets of practices key to the colonial project, the disembodied god's-eye-view of Enlightenment science and the idealized subject-body of the colonizer. These subject positions materialize the entangled logics of observation and occupation.

\section{TMT: Road to the cosmos}

Mauna Kea is emblematic of the larger struggle over Hawai'i: a struggle over meanings assigned to land and thus the struggle for control over space. (Casumbal-Salazar, 2014: 32)

TMT, proposed for construction atop Maunakea, would be the largest visible-light telescope on Earth. Visible-light telescopes gather light in curved mirrors and lenses and concentrate it for the observer. Larger mirrors collect more light so fainter, more distant objects can be viewed. The primary mirror of TMT is planned at 30 meters across, making it "three times as wide, with nine times more area, than the largest existing visible-light telescope in the world" (Mauna Kea and TMT, n.d.). This massive mirror would actually be composed of 492 perfectly polished reflective elements that work as one to create a light collection area of 655 square meters, generating a signal 12 times sharper than the Hubble Telescope. This is an impressive feat given that Hubble moves through the vacuum of space, while TMT must contend with all the noise of an earthly existence - light pollution, cloud cover, atmospheric turbulence. The spectacle of TMT as a cosmic observing apparatus is irrefutable (see Figure 1).

Yet, expanding the bounds of the telescope apparatus to include its enrollment of place on a colonized island mountain demonstrates how TMT cannot be understood apart from colonial projects of state-building and land theft (Hobart, 2019; Mitchell, 2018), any more than it can be separated from its specific physical attributes. These practices do not just make the scientific work of TMT possible, they are inextricably entangled in the very logics

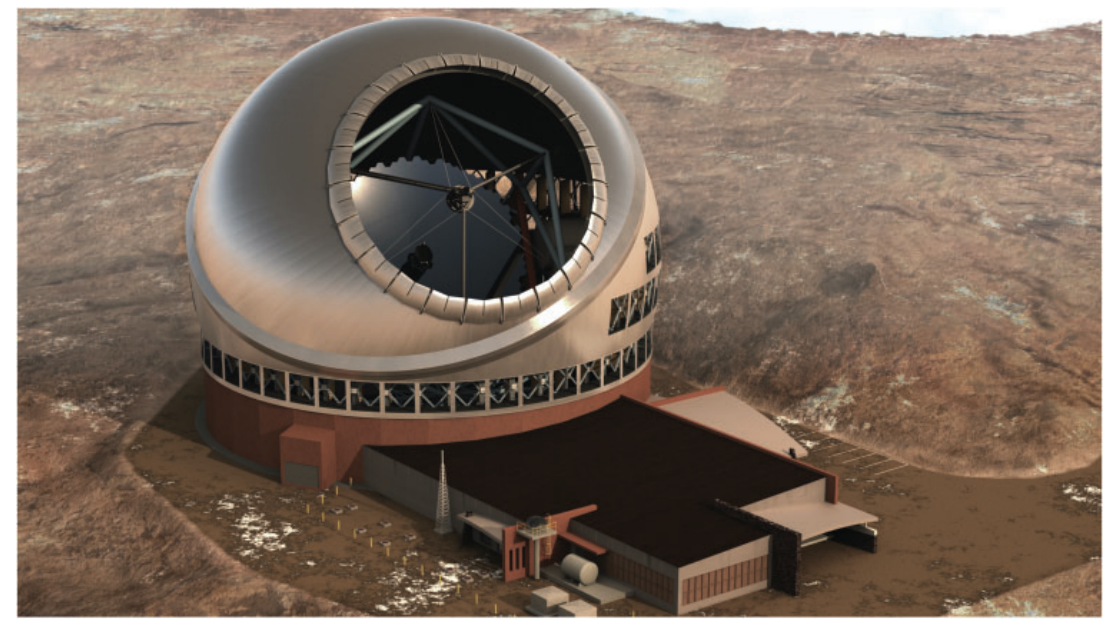

Figure I. Digital rendition of the TMT dome proposed to be built on Maunakea. Image source: Courtesy TMT International Observatory. 
of observation. The entirety of the apparatus is necessary to enact an agential separability, constituting subject-object relations in which the subjects' aim is power and the reproduction of the colony.

TMT would allow astronomers to peer deeper into space and further back in time than ever before, exploring "first-light" objects and the physics of the early universe. The light that TMT aims to capture comes from distant cosmos and even light travelling at $300,000 \mathrm{~km} / \mathrm{s}$ takes time to traverse the immense distances of the universe. Collecting photons from the cosmic beginning, 13 billion years ago, puts such endeavors in the realm of cosmological time, imagined as apolitical. The telescope constructs a linear time progression backwards towards the origins of the universe while evacuating the specificity of existing spatial relations on the island mountain. Vested interests in space science infrastructure also invoke the linear temporalities of progressive futures, a self-naturalizing, teleological temporality. Inherent in this formulation is the relegation of Indigeneity to the past, that which is historical or even ahistorical (Rifkin, 2017), not within the manifest destiny of Western astronomical knowledges or a "manned" Mars per se.

Cook's observation of the transit of Venus was actually the planet's shadow crossing the Sun. It took eight minutes for this light to reach Cook's lens. Such temporal latency illustrates the time it takes for information (light) to travel between observer and observed. Latency is a delay in information transfer, an untimeliness. Cook's telescope introduces a protracted relationship between subject and object, altering the spatial and temporal correspondence. For large modern telescopes, this interval drastically increases. The light collected has a history; the astronomer views old light. As Cook measured Venus' transit time to calculate distances between bodies, in astronomy, looking farther into space equates to looking at objects in another time, as space and the reach of time expand with the universe. A telescope allows observers to view objects at incredible distances and from different times, expanding distances between subject and object, producing the experience of a god's eye view, an Archimedean point. As Messeri points out, "Observing from the Archimedean point requires astronomers to cognitively inhabit this point" (2016: 185, emphasis in original). This repositions astronomers in the abstract, forgoing their place in the cosmos. Yet, Messeri describes how many astronomers do not just seek "to understand our place in the universe" but imagine "the potential for all planets to be worlds" (2016: 187) and thus occupy those worlds with colonial imaginaries. The analytic of the apparatus in conversation with anti-colonial critiques show how space science epistemologies do not just rely on spatial logics of separability, but are produced through the same material practices that seek to order space-times into colonial relations. Astronomers do not just cognitively inhabit the Archimedean point, but produce material sites and infrastructures that enable this perspective.

The Archimedean point is materially produced at TMT through the abstraction of Maunakea into a set of specific measurable variables. A board of scientists selected Maunakea "after a rigorous five-year campaign spanning the entire globe that measured virtually every atmospheric feature that might affect the performance of the telescope" (TMT International Observatory, n.d.). Through the lens of space sciences, the island mountain is understood through variables that define its location as superior observation site. At 4200 meters above sea level, Maunakea's summit, and the telescope's mirrors, is above $40 \%$ of Earth's atmosphere and $90 \%$ of atmospheric water vapor. Its location, as an island far out in the ocean, keeps light pollution low, and the sea's thermal inertia combined with the slopes of the shield volcano becalms the atmosphere, reducing turbulence that obscures cosmic signals. As one University of Hawai'i astronomer (Hall, 1989: 243), 
promoted the location, "[t]he typical astronomical characteristics of Mauna Kea are summarized [as]:

elevation $4.2 \mathrm{~km}$

pressure $616 \mathrm{mb}$

latitude $+20^{\circ}$

dark sky $\sim 50 \%$ photometric nights

$\sim 70 \%$ useful nights

low $\mathrm{H}_{2} \mathrm{O}$ and IR emissivity

excellent image quality."

These conditions brand Maunakea as the clearest ground-view of the universe, where Earth encounters cosmos. An article titled Mauna Kea (I): Halfway to Space characterizes the shield volcanoes of Hawaii as "broad, solitary structures, like isolated probes of the dry upper air" (Waldrop, 1981: 1010). Abstracting individual variables evacuates a lived place of its relationality, plurality, and intersubjectivity, "wherein the scientific experiment requires unruly variables be removed in order to isolate the desired data sets" (Casumbal-Salazar, 2014: 137). By isolating these variables, the politics of place are erased and the violent dispossession of land is sanitized as a function of "a settler society that continually asserts its totalizing authority over lands, space, and time" (Byrd, 2011: 187). This is how the Archimedean point is materialized in a real place.

The proposed telescope has sparked vigorous protest and legal battles from Native Hawaiian land protectors that wish to safeguard this sacred site from further development. As Hobart explains: "its landscape has suffered a process of deanimation across the nineteenth and twentieth centuries, when discourses of absence have systematically produced the Mauna as a place without humans, spirituality, nation, or even atmosphere" (2019: 31). The first telescopes were built on occupied lands of the mountain in the late 1960s as a form of economic development for the new state (Hawai'i gained statehood in 1959). Maunakea was recognized for its clear skies by a scientist at the weather station on the neighboring peak, Maunaloa, who reported his observation to the Hawai'i Island Chamber of Commerce. Seeing an opportunity for development, this friend sent letters to all large universities in the U.S. and to University of Tokyo. Gerard Kuiper, a planetary scientist from University of Chicago who had worked on Air Force project A119 to detonate a nuclear warhead on Moon, was the only respondent. He arrived in Hawai'i and explored the peak via aircraft, and then by jeep, which could not reach the summit as there was no road. Hawaii's governor agreed to fund road construction, towards an economic boost, on lands ceded by the Republic of Hawai'i to the federal government after the illegal overthrow of the Hawaiian government by plantation owners and missionary descendants in 1893.

Built in 1964, the road enabled summit development and in 1967 the "Astronomy Precinct" was established upon land protected by the 1966 National Historic Preservation Act for its cultural significance. The precinct encompasses 525 acres and now includes 13 observatories and research facilities (Office of Maunakea Management, n.d.). This road is also a site of resistance. Here a blockade of "collective refusal" prevents the groundbreaking 
for the construction of the 14th observatory, and more broadly "challenges a half-century [of] disregard for this sacred site by numerous entities and interests ... [continuing] a larger fight against colonial occupation and the role of infrastructure in maintaining the cultural, spiritual, and political hegemonies that produce it" (Matson and Nunn, 2017: n.p.). Long before TMT was proposed, the summit road and the Astronomy Precinct formed part of its broader apparatus encompassing histories of colonial land tenure, systems of capitalist economic development, university research centers, and the mountain's physical, atmospheric, and meteorological characteristics. TMT represents the apex of observation systems while simultaneously securing continued occupation of the mountain and Hawai'i for colonial interests. The TMT project aims to order infrastructural spacetimes on Hawai'i to create an accessible Archimedean point for ordering the cosmos. The observation facilities of the Astronomy Precinct and the knowledge it produces cannot be separated from the access road and the stolen lands upon which it sits. It physically manifests connections between observation and occupation, between space science epistemology and the material ordering of settler colonial spacetimes.

By recognizing the Archimedean point as not just a cognitive construction but produced by material and spatial arrangements that are inextricable from their colonial entanglements, we can also draw attention to the limits and contingency of these arrangements and their potential to be disrupted. The tension between the ephemerality of an imagined view-from-nowhere and its physical manifestation opens up spacetimes for its unsettling. The road to Maunakea's summit also constitutes part of an apparatus of resistance. Kia $i$ began blocking it in 2019 - only the latest in a long history of activism and peaceful resistance (Long, 2019). The history of Kanaka Maoli opposition to colonial occupation dates back to early contact with Cook. Since this encounter, many Native Hawaiians have refused colonial occupation projects from privatization and plantations, to annexation and militarization (Casumbal-Salazar, 2014; Chang, 2016). Several kia'i actions protected the mountain from construction in 2015 and 2019, but also date back to the beginning of development in the 1960s. Moreover, this is not the only peak where Kanaka Maoli have struggled against space science infrastructural development. The world's largest solar telescope sits atop Haleakalā, the highest mountain on Maui. The summit development, called Science City, was also created during Hawaii's early statehood and now consists of 10 observation facilities.

On Maunaloa, a very different set of space science observations are taking place. Whereas TMT aims to materialize conditions for an Archimedean point, HI-SEAS fashions an apparatus to distill ideal colonizer-subjects based on similar logics and practices of abstraction but that makes different agential cuts. Taking as its object the individual bodies and psyches of would-be astronaut-colonizers, it surveilles and shapes their embodied relationships to the spaces they inhabit.

\section{HI-SEAS: Simulation and surveillance}

HI-SEAS is a 110 square meter dome located 2500 meters above sea level on the slopes of Maunaloa (see Figure 2). It serves as an analog of an offworld habitat, part of broader public and private transnational projects focused on future offworld colonization. Reflecting Hobart's (2019) explanation of how Western imaginaries of emptiness are employed to justify colonial projects, this site was selected to simulate Mars as it purportedly "contains little vegetation, no rare, threatened or endangered species, and no archaeological sites or cultural practices" (HI-SEAS, 2019). 


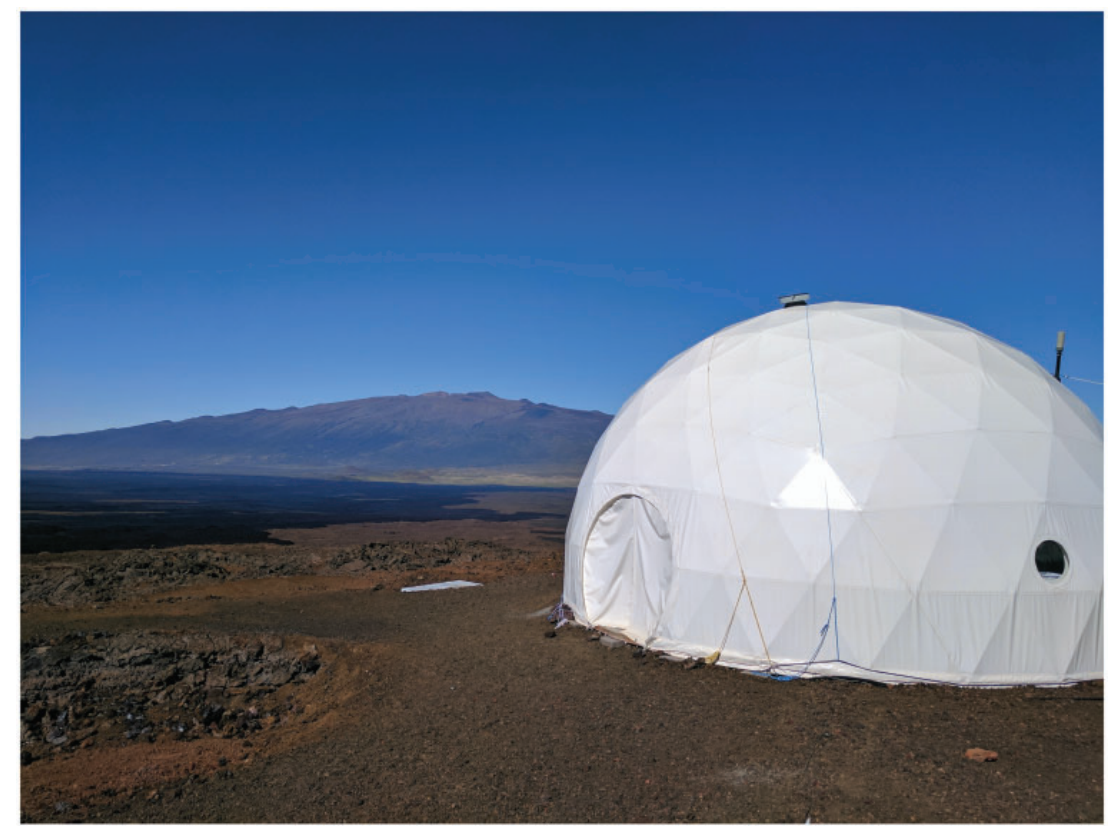

Figure 2. HI-SEAS habitat on Maunaloa with Maunakea in the background. Image source: University of Hawai'i News (Flickr. Creative Commons: Attribution-NonCommercial-NoDerivs 2.0).

Analogs of offworld environments play an important role in planning future outer space activities (Messeri, 2014; Olson, 2018). Many locations on Hawai'i have long served as offplanet analogs allowing scientists and engineers to test space technology. As the International Moonbase Alliance (2019: n.p.) explains:

During the 1960s, NASA had first trained Apollo astronauts and tested the lunar rover systems on Hawai'i Island, regarding the area as one of the most realistic terrestrial lunar-like they had found, due to the high altitude with greater solar radiation intensity, dry environment weather conditions, and availability of lunar regolith-like deposits of volcanic ash.

Noticeably, the site's complex realities are erased, while a small set of particular variables are isolated to be enrolled in broader apparatuses. The site was chosen for what is described as, "Mars-like geology which allows crews to perform high-fidelity geological field work and add to the realism of the mission simulation" (HI-SEAS, 2019). Other key variables were the site's purported distance and isolation from "civilization" yet simultaneous proximity to major research hubs at the University of Hawai'i, Hilo (UHH) (PISCES, n.d.). Controlling key environmental factors allows for "the governance of colonized spaces deemed threatening but also adaptively vitalizing for European bodies and sensibilities" (Olson, 2018: 46). In this case, deanimating the immediate environment works towards vitalizing offworld bodies and colonizing sensibilities.

Between 2013 and 2018, HI-SEAS hosted six missions managed by UHH and sponsored by NASA to collect data about different aspects of future Mars colonization. Each HISEAS crew, between four and six cadets, entered the dome to live and work for a period of 
four months to a year. The habitat operations mimic several aspects of an offworld colony. The promoters explain:

We have developed a robust system of high-latency communication between Crew and Mission Support that imposes a Mars-like 20-minute delay on message reception each way. Communication is solely asynchronous ... and other mission parameters can be varied according to study requirements. (HI-SEAS, 2019)

These mission features allow researchers to study questions of logistics, teamwork, and crew psychology for future Mars missions.

HI-SEAS habitat was built for observing human behavior under extreme conditions of solitude, to overcome behavioral health and performance elements associated with the unique demands of exploration missions and risks related to future long-duration space flight. While the cadets conduct a range of experiments during their missions, the primary purpose was to observe crew members and their behavior. As Koren makes clear in her reporting for The Atlantic:

HI-SEAS is a social experiment, and the participants are the lab rats. They wear devices to track their vitals, movements, and sleep, answer countless questionnaires about their own behavior and their interactions with others, and journal several times a week about their feelings. (2018: n.p.)

Where TMT occupies Maunakea for far-off cosmic observations, HI-SEAS observes intimate, embodied, and psychological experiences of its crew towards advancing offworld occupation.

These arrangements actively control bodies and movements to produce particular kinds of subject-object relations. In this case, the apparatus of the habitat turns crew members into the object of systems of surveillance, while working to constitute them as particular kinds of disciplined subjects - future colonizers of the cosmos. This insight helps unpack the settler colonial subjectivities of those working in space science who often refer to "human 'destiny' to colonize space" (Olson, 2018: 94) or justify their actions by invoking a purportedly universal good of "exploration" (Messeri, 2016: 18). The analytic of the apparatus helps us trace the material and embodied practices through which those subject positions are fostered and systems are developed to better produce such subjects in the future.

Within HI-SEAS missions, researchers experimented with virtual reality (VR) goggles to combat behavioral health concerns and offer relief from the purported seclusion and monotony of the red, rocky "offworld" landscape. The New York Times (Koppel, et al., 2017) documented crew experiences with their own VR chronicles, where readers can join trainees in the dome and access their VR therapy. As the science officer trainee straps on a VR headset, he describes how

Putting the VR on... is strange. It's so overwhelming to have that much sensory input... As soon as you put the VR headset on, you kind of really get sucked into this kind of different world and forget that you're in a dome on the side of a volcano.

Crew members can choose from varied resplendent Earth visuals, such as teeming parks and cityscapes, hushed snow-covered fields, and sumptuous green forests. As the engineering officer trainee interprets her VR episodes, "It is sometimes easy to forget where you actually are, and that's a really interesting feeling, to sort of be nowhere." Within this experiment, trainees are encountering a copy of Earth, while within a model of Mars, forgetting their 
place in a dome on a Hawaiian mountain. The VR experience helps reinforce a separateness - the constitutive "nowhere" of Western science - through a set of material and bodily arrangements that produce and orient colonizer-subjectivities in relation to spaces they inhabit. The project collects these cadets' experiential data to develop systems toward managing and disciplining future settler bodies - to produce an idealized subject for offworld colonies.

HI-SEAS crew members conducted geological explorations and surveys to model teamwork and logistical processes for future Mars missions. One program designer clarifies:

We have designed a series of geology-related EVA [extravehicular activity] tasks that we assign regularly to the crew. Each task serves as a mini research project for the crew, who must devise how to gather data and solve the given problem with minimal interaction or direction from mission support. The team-oriented tasks are designed to be gradable with quantifiable metrics so that meaningful conclusions about crew performance on missions of varying length can be drawn. (Engler, 2017: n.p.).

These exercises imagine that crewmembers on future Mars missions may not be practicing geologists and will likely have limited previous knowledge about the geological conditions in which they find themselves. They simulate how crewmembers would produce geological knowledge as Mars explorers, observing their surroundings using simple tools, wearing spacesuits, and functioning with minimal communication. Olson (2018) notes how imaginaries of offworld colonies require subjects to see themselves playing multiple roles, such as a physician that may also play secondary roles as navigator, robot repairer, or geologist. HI-SEAS prepares colonizers to be adaptable subjects within this architype frontier setting.

These missions do not produce new knowledge about Maunaloa's geology, but rather about crew behaviors and practices. Crewmembers were specifically instructed not to research the geology of Maunaloa before starting the mission. Oleg Abramov, Chief Geologist on the first mission in 2013, explains how he first conducted a general survey and collected mineral samples. He classified minerals creating a geological map of the habitat area. He notes the color and texture of minerals and different ages of lava flow and the presence of lava tubes making certain areas of terrain un-traversable (Abramov, 2013: n.p.). Through their research, crew members worked to produce multiple apparatuses of observation. Geological exercises, donning space suits, communications devices, sampling tools, and maps they produced constitute an apparatus allowing them to know and thus control their surrounding environment. As Olson explains: "In this colonial model of spacefaring as a species destiny, a collective human future is shaped by interactions between exploring groups and the inhuman nonterrestrial ecologies they make and adapt to" (2018: 94) The geological exercises are an apparatus meant to orient such human-ecological relations. These apparatuses re-order space, time, and matter to produce disciplined colonizer-subjects and orient relationships to their surrounding environments. As with TMT, the landscape is deconstructed to constituent variables in order to construct the perfect observation point. The knowledge produced ensures the orderly, productive, and scientific conduct of future colonizers while erasing ongoing disciplining and forced assimilation of existing colonial subjects.

Just as Cook's voyage formed part of a broader apparatus of exploration and colonization, HI-SEAS connects to extensive apparatuses, largely in Europe and the United States, actively planning offworld colonization. The dome was built in 2013 by Henk Rogers, a Dutch video game developer who made most of his money from Tetris licensing rights. As Koren reports: "Henk Rogers made his money designing computer games, but he is 
passionate about space exploration, and particularly the idea of constructing human settlements on other worlds. Life on Earth, just like his computers, needs a backup, he has said" (2018: n.p.). Rogers founded the International Moonbase Alliance and is Chairman of the Pacific International Space Center for Exploration Systems, or PISCES. He ascribes to a vision of offworld colonization common among wealthy tech entrepreneurs like Elon Musk and Jeff Bezos who see human colonies on Mars or Moon as vital for the future survival of the species. For them, the survival of the species rests in an inevitable march toward "progress," necessitating offworld colonization and thus the production of ideal disciplined colonizer-subjects.

Through simulations like HI-SEAS and the data they produce, subjects are prepared to "start over" on a purported blank slate. Within this vision, major actors in private, offplanet colonization debate the merits of focusing primarily on Mars, or on first colonizing Moon as a "stepping-stone or place to practice" (International MoonBase Alliance, 2019: n.p.). Rogers' imaginary of future colonization projects a very particular subject in these activities, specifically private enterprises and their employees, while orienting those subjects to the spaces they encounter by evacuating those spaces of any meaning. He writes (2019: n.p.):

Once you get to the Moon, nobody owns that space. Another way to look at it is like the West India Company, where government played a part in outreach but it was really this private company looking for resources from the new world that played a bigger role.

Rogers' statement reflects how offworld colonization is uncritically projected as the continuation of long-running historical processes of settler colonization, extrapolated out from "The Doctrine of Discovery." Framing HI-SEAS in the same rhetoric helps make clear what kinds of relationships to offworld environments Rogers and others like him are working to facilitate and what kinds of actors are meant to lead these projects.

The sixth Mars simulation mission at HI-SEAS was abruptly cut short in February 2018 after one of the four crew members sustained injuries from electric shock while turning on a backup generator. After an investigation by NASA and $\mathrm{UHH}$, this mission and all future missions were eventually canceled. Like blockades of TMT's access road, the electrocution disrupted HI-SEAS as an apparatus producing disciplined colonizer-subjects. The fragility of the human body and the unachievable goal of the ideal colonizer-subject reveals the contingent and partial nature of all such projects. Yet, since the cancellation of the mission, HI-SEAS has been reconstituted as a Moon analog within the EuroMoonMars initiative - a partnership between the European Space Agency, International Lunar Exploration Working Group, International Moonbase Alliance, and other public and private actors. The project continues with simulation experiments meant to develop logistical procedures for offworld colonization. Just as the crew of the habitat changes, the controlling interests are also reshuffled. Even the planetary targets to be colonized get swapped out. What remains are agential cuts producing specific subject-object relations, in this case idealized colonizer-subjects and their embodied orientations towards the colony they may one day inhabit, erasing the colony they currently occupy.

\section{Conclusion}

One scientist told me that astronomy is a 'benign science' because it is based on observation, and that it is universally beneficial because it offers 'basic human knowledge' that everyone should know 'like human anatomy.' (Casumbal-Salazar, 2017: 8) 
This paper has shown how focusing on the apparatuses - the infrastructures, sites, bodies, and relations - through which observation is conducted demonstrates the active material practices necessary for any scientific endeavor. Observation is never passive, but enrolls the apparatus to create a distance that iteratively constitutes relations of objectivity and subjectivity. Observation as an ostensibly passive activity of knowledge production is key to astronomy's claim to universality. Yet, observation enacts a key spatio-temporal relationship - an agential separability between subject and object of observation, be it the observation of a human body or a far-off galaxy. The observing subject is of course located somewhere, but the specificity of this site and its socio-material entanglements is erased through the enactment of a view-from-nowhere in the production of "universal" knowledge (Hobart, 2019). Casumbal-Salazar illustrates how claims of universality, "function to rationalize settlement and mask the historical theft and continued power relations that comprise settler colonialism" (2014: 180-181). Lempert similarly argues that "assumptions around the inculpability of 'passive' engagement... although presented as morally virtuous, ultimately serves the broader interests of empire" (2019: n.p.).

Understanding HI-SEAS and TMT as apparatuses highlights how the enactment of agential separability to claim objectivity involves active reorderings of space, time, and matter that rely upon existing colonial relations and reproduce their logics. Colonial occupation around the globe, including the Pacific Islands, constitutes the basic conditions for scientific practices of observation beginning in the 18th and 19th centuries. Yet, the contingencies of the colonial context constantly threaten to undermine this "viewfrom-nowhere" logic. The persistent presence of Kanaka Maoli, their sovereign right to land, and continued demands to a future, act as an ongoing check on any claims to universality or settler futurity. Goodyear-Ka'ōpua, for instance, explains how "settler state officials cast the kia'i as impediments on the road to "progress' (aka settler futurity)" (2017: 191). This is not to pose a singular Native Hawai'ian perspective as somehow in opposition to Western science, but to recognize how colonialism relies on the assimilation of difference in the projection of "universal" settler futures.

It is precisely the assimilation of difference - though in a different form - that is HISEAS' objective. Offworld colonization will require disciplined subjects. This project is based on the continued desire for a "clean slate" from which the elusive ideals of the Enlightenment might be achieved. As Valentine writes regarding visions of offworld colonies:

they also hold out a libertarian hope that conscious effort and free enterprise in places whereas I have frequently heard said - "there are no natives" will fix things so that humans can do a more equitable job of colonialism this time around... The problems of terrestrial history, human difference, and equality, that is, could be finally settled and fixed elsewhere in the cosmos. (2017: 187)

In other words, "it's as if the only thing wrong with colonialism was that people were already living there" (Shorter, 2019a). Mars and/or Moon are envisioned as the next site of human colonization without any recognition of the disastrous history, and ongoing calamity, of settler colonialism on Earth. The lack of reflexivity is not accidental; colonial relations are built into and reproduced through the apparatuses that might make such projects possible. Tracing the production of apparatuses raises questions of what kind of worlds are being produced, and for whose benefit. Ethics thus entails questions of responsibility for the kinds of apparatuses enacted and the ways they produce difference. 
Reflecting on the SSOS literature, this paper has shown how questioning the ethics of space science requires an examination of the apparatuses assembled, the nature of those apparatuses, and the ways they iteratively reshape the world and what comes to matter. Shorter argues that "[t]hose leading the U.S. quest for galactic exploration utilize unethical methods that they base in colonial and anthropocentric theories for the purposes of resource extraction" (2019b: n.p.). Colonial relations of domination are (re)produced through the assembling of apparatuses in particular places and the coordinated efforts of putting them to work in the service of colonial expansion to offplanet spaces. SSOS literature needs to be explicitly anti-colonial, as coloniality is foundational to the practices of contemporary space science and imaginaries of space "exploration." There cannot be an ethical engagement with the lands of other planets when the sciences are rooted in exploitative colonial relations on Earth. Such projects will always be colonies.

\section{Acknowledgements}

Early versions of this paper were presented at the International Small Islands Studies Association's 16th Islands of the World Conference in 2018, and the coconvened Canadian Association of Geographers and International Geographical Union Regional Meeting in 2018 supported by an AAG NSF IGU Conference Travel Grant. We are grateful for thoughtful engagement from session presenters and attendees at these sessions. Thank you to Drs. Sarah Senk and Tom Nurmi for their careful readings and offering comments on structure and content. Special thanks Dr. Lily HousePeters for comradery in navigating lava tubes and dome habitats.

We are indebted to Dr. Michelle L. Shuey and her Geography and Environmental Science students from University of Hawai'i Hilo for kindness and hospitality. We thank the three anonymous reviewers and the editor, Natalie Oswin, for their thoughtful feedback which helped improve and clarify the focus of the paper. Finally, we would like to express gratitude to all land and water protectors.

\section{Declaration of conflicting interests}

The author(s) declared no potential conflicts of interest with respect to the research, authorship, and/ or publication of this article.

\section{Funding}

The author(s) disclosed receipt of the following financial support for the research, authorship, and/or publication of this article: Research funding was provided by the California State University Chancellor's Office Research, Scholarship and Creative Activities Award (RSCA) via CSU Maritime. We acknowledge support by the Open Access Publication Funds of Alfred-WegenerInstitut Helmholtz- Zentrum für Polar-und Meeresforschung.

\section{ORCID iD}

Katherine G Sammler (D) https://orcid.org/0000-0003-0404-7597

\section{References}

Abramov O (2013) Geological exploration. HI-SEAS, 6 May. Available at: https://hi-seas.org/?p= 1432 (accessed 18 August 2021).

Allen TM (2008) A Republic in Time: Temporality and Social Imagination in Nineteenth-Century America. Chapel Hill: University of North Carolina Press.

Baldacchino G (2007) Islands as novelty sites. Geographical Review 97(2): 165-174.

Barad K (2007) Meeting the Universe Halfway: Quantum Physics and the Entanglement of Matter and Meaning. Durham: Duke University Press. 
Brown MA (2016) Mauna Kea: Ho'omana Hawai'i and protecting the sacred. Journal for the Study of Religion, Nature \& Culture 10(2): 150-169.

Byrd JA (2011) The Transit of Empire: Indigenous Critiques of Colonialism. Minneapolis: University of Minnesota Press.

Casumbal-Salazar I (2014) Multicultural settler colonialism and Indigenous struggle in Hawai' $i$ : The politics of astronomy on Mauna a Wākea. PhD Thesis, University of Hawai'i at Mānoa, USA.

Casumbal-Salazar I (2017) A fictive kinship: Making "Modernity," "Ancient Hawaiians," and the telescopes on Mauna Kea. Native American and Indigenous Studies 4(2): 1-30.

Chang DA (2016) The World and All the Things upon It. Minneapolis: University of Minnesota Press.

DeLoughrey EM (2012) The myth of isolates: Ecosystem ecologies in the nuclear Pacific. Cultural Geographies 20(2): 167-184.

Dunnett O, Maclaren AS, Klinger J, et al. (2019) Geographies of outer space: Progress and new opportunities. Progress in Human Geography 43(2): 314-336.

Engler S (2017) Asynchronous Geological Exploration Operations at the HI-SEAS Planetary Surface Analog Mission Simulation in Hawai'i. HI-SEAS, 3 January. Available at: https://hi-seas.org/?p= 6076 (accessed 18 August 2021).

Farbotko C (2010) Wishful sinking: Disappearing islands, climate refugees and cosmopolitan experimentation. Asia Pacific Viewpoint 51(1): 47-60.

Goldberg-Hiller J and Silva NK (2015) The botany of emergence: Kanaka ontology and biocolonialism in Hawai'i. Native American and Indigenous Studies 2(2): 1-26.

Goodyear-Ka'Öpua N (2017) Protectors of the future, not protestors of the past: Indigenous Pacific activism and Mauna a Wākea. South Atlantic Quarterly 116(1): 184-194.

Greenhough B (2006) Tales of an island-laboratory: Defining the field in geography and science studies. Transactions of the Institute of British Geographers 31(2): 224-237.

Hall DNB (1989) Characteristics of Mauna Kea relating to the Japan National Large telescope. Astrophysics and Space Science 160(1-2): 243-248.

Haraway D (1988) Situated Knowledges: The science question in Feminism and the Privilege of Partial Perspective. Feminist Studies 14(3): 575-599.

HI-SEAS (2019) HI-SEAS. Available at: https://hi-seas.org/ (accessed 18 August 2021).

Hobart HJ (2019) At home on the Mauna: Ecological violence and fantasies of Terra Nullius on Maunakea summit. Journal of the Native American and Indigenous Studies Association 6(2): 30-50.

Immerwahr D (2019) How to Hide an Empire: A History of the Greater United States. New York: Picador.

International MoonBase Alliance (2019) Henk Rogers - International MoonBase Alliance. Available at: https://moonbasealliance.com/henk-rogers (accessed 18 August 2021).

Klinger JM (2021) Environmental geopolitics and outer space. Geopolitics, 26(3): 666-703.

Koppel N, Capezzera N and Shastri V (2017) Life on Mars. The New York Times, 31 May. Available at: www.nytimes.com/interactive/2017/05/31/science/space/life-on-mars.html (accessed 18 August 2021).

Koren M (2018) Hawaii's Mars simulations are turning into moon missions. The Atlantic, 20 November. Available at: www.theatlantic.com/science/archive/2018/11/hi-seas-mars-habitatnasa-moon-simulation/576295 (accessed 18 August 2021).

Lempert W (2019) Interstellar imperialism: Joseph Banks, prime directives, and the fatal conceit of ET contact. In: Native American and Indigenous studies association conference, Hamilton, Aotearoa, New Zealand, 26-29 June 2019.

Long KK (2019) The fight of the Indigenous protectors of Mauna Kea. The Funambulist 25.Accessed at: https://thefunambulist.net/magazine/25-self-defense/the-fight-of-the-indigenous-protectors-ofmauna-kea-by-k-kamakaokailima-long

Lynch CR (2017) "Vote with your feet": Neoliberalism, the democratic nation-state, and utopian enclave libertarianism. Political Geography 59: 82-91.

Maile D (2015) Science, time, and Mauna a Wākea: The Thirty-Meter Telescope's capitalist-colonialist violence, part I. The Red Nation. Available at: https://therednation.org/science-time-and-mauna-a- 
wakea-the-thirty-meter-telescopes-capitalist-colonialist-violence-an-essay-in-two-parts/(accessed 24 August 2021)

Matson ZM and Nunn N (2017) Space infrastructure, empire, and the final frontier: What the Mauna Kea Land defenders teach us about colonial totality. Society and Space, Available at: https://www. societyandspace.org/articles/space-infrastructure-empire-and-the-final-frontier-what-the-maunakea-land-defenders-teach-us-about-colonial-totality (accessed 24 August 2021)

Matsuda MK (2006) The Pacific. The American Historical Review 111(3): 758-780.

Matsuda MK (2007) “This territory was not empty": Pacific possibilities. Geographical Review 97(2): 230-243.

Mauna Kea and TMT (n.d.) Available at: www.maunakeaandtmt.org (accessed 18 August 2021).

Messeri L (2014) Earth as analog: The disciplinary debate and astronaut training that took geology to the moon. Astropolitics 12(2--3): 196-209.

Messeri L (2016) Placing Outer Space: An Earthly Ethnography of Other Worlds. Duke University Press.

Mirmalek Z (2020) Making Time on Mars. Cambridge, MA: The MIT Press.

Mitchell ST (2018) Constellations of Inequality: Space, Race, and Utopia in Brazil. Chicago, IL: The University of Chicago Press.

Office of Maunakea Management (n.d.) Available at: www.malamamaunakea.org/science/astronomy (accessed 18 August 2021).

Olson V (2018) Into the Extreme: U.S. Environmental Systems and Politics beyond Earth. Minneapolis: University of Minnesota Press.

PISCES (n.d.) Available at: https://moonbasealliance.com/pisces (accessed 18 August 2021).

Prescod-Weinstein C, Walkowicz LM, Tuttle S, et al. (2020) Reframing astronomical research through an anticolonial lens - For TMT and beyond. Preprint. https://doi.org/10.6084/m9.figshare. 11522295.v1

Redfield P (2002) The half-life of empire in outer space. Social Studies of Science 32(5/6): 791-825.

Rifkin M (2017) Beyond Settler Time: Temporal Sovereignty and Indigenous Self-Determination. Durham: Duke University Press.

Salmond A (2003) The Trial of the Cannibal Dog: The Remarkable Story of Captain Cook's Encounter in the South Seas. New Haven: Yale University Press.

Sammler K and Lynch C (2019) Spaceport America: Contested offworld access and the everyman astronaut. Geopolitics 26(3): 704-728.

Shaw MN (2003) International Law. Cambridge: Cambridge University Press.

Shorter D (2019a) Object orientated science and the fantasy of alien contact. In: Native American and Indigenous Studies Association annual conference, Hamilton, Aotearoa, New Zealand, 26-29 June 2019

Shorter D (2019b) Settler science and searches for intelligence: Decolonizing "contact". Panel session at Native American and Indigenous Studies Association annual conference, Hamilton, Aotearoa New Zealand, 26-29 June 2019.

Smiles D (2020) The settler logics of (outer) space. Society \& Space. Available at: www.societyand space.org/articles/the-settler-logics-of-outer-space (accessed 18 August 2021).

TMT International Observatory (n.d.) Available at: www.tmt.org/ (accessed 18 August 2021).

Valentine D (2017) Gravity fixes: Habituating to the human on Mars and island three. Hau: Journal of Ethnographic Theory 7(3): 185-209.

Vertesi J (2015) Seeing like a Rover: How Robots, Teams, and Images Craft Knowledge of Mars. Chicago, IL: University of Chicago Press.

Waldrop MM (1981) Mauna Kea (i): Halfway to space. Science (New York, N.Y.) 214(4524): $1010-1013$.

Watts V (2013) Indigenous place-thought and agency amongst humans and non humans. Decolonization: Indigeneity, Education \& Society 2(1): 20-24.

Yaqoob W (2014) The Archimedean point: Science and technology in the thought of Hannah Arendt, 1951-1963. Journal of European Studies 44(3): 199-224. 
Katherine G Sammler leads the Marine Political Ecology group at the Helmholtz Institute for Functional Marine Biodiversity (HIFMB) in partnership with the Alfred Wegener Institute for Polar and Marine Research (AWI) and University of Oldenburg in Germany. Working as a human and political geographer, previously trained in physics and atmospheric sciences, our research lies at the intersection of science and politics in the realm of oceans, atmospheres, and outer space. In all areas, our work considers the role of knowledge production, law, and power in defining global commons, access, and environmental justice.

Casey R. Lynch is Assistant Professor in the Department of Geography at the University of Nevada, Reno. His research examines the politics of urban social and technological change, with a focus on emerging digital technologies and competing visions of the futures they enable. His current work considers the development and deployment of socially-interactive robots in the spaces of everyday life, as well as the use of blockchain technology in remaking urban economies and government. 